\title{
The vulnerability evolution and simulation of social-ecological systems in a semi-arid area: A case study of Yulin City, China
}

\author{
CHEN Jia ${ }^{1,2}$, "YANG Xinjun ${ }^{1,2}$, YIN Sha ${ }^{1}$, WU Kongsen ${ }^{1}$, DENG Mengqi ${ }^{1}$, WEN Xin ${ }^{1}$ \\ 1. College of Urban and Environmental Sciences, Northwest University, Xi'an 710127, China; \\ 2. Shaanxi Key Laboratory of Earth Surface System and Environmental Carrying Capacity, Northwest Univer- \\ sity, Xi'an 710127, China
}

\begin{abstract}
Taking the semi-arid area of Yulin City as an example, this study improves the vulnerability assessment methods and techniques at the county scale using the VSD (Vulnerability Scoping Diagram) assessment framework, integrates the VSD framework and the SERV (Spatially Explicit Resilience-Vulnerability) model, and decomposes the system vulnerability into three dimensions, i.e., exposure, sensitivity and adaptive capacity. Firstly, with the full understanding of the background and exposure risk source of the research area, the vulnerability indexes were screened by the SERV model, and the index system was constructed to assess the characteristics of the local eco-environment. Secondly, with the aid of RS and GIS, this study measured the spatial differentiation and evolution of the social-ecological systems in Yulin City during 2000-2015 and explored intrinsic reasons for the spatial-temporal evolution of vulnerability. The results are as follows: (1) The spatial pattern of Yulin City's SESs vulnerability is "high in northwest and southeast and low along the Great Wall". Although the degree of system vulnerability decreased significantly during the study period and the system development trend improved, there is a sharp spatial difference between the system vulnerability and exposure risk. (2) The evolution of system vulnerability is influenced by the risk factors of exposure, and the regional vulnerability and the spatial heterogeneity of exposure risk are affected by the social sensitivity, economic adaptive capacity and other factors. Finally, according to the uncertainty of decision makers, the future scenarios of regional vulnerability are simulated under different decision risks by taking advantage of the OWA multi-criteria algorithm, and the vulnerability of the regional system under different development directions was predicted based on the decision makers' rational risk interval.
\end{abstract}

Keywords: social-ecological systems (SESs); VSD assessment framework; vulnerability; Yulin City

\section{Introduction}

Arid and semi-arid regions are sensitive to global environmental change (IPCC, 2014). In

Received: 2017-06-16 Accepted: 2017-07-30

Foundation: National Natural Science Foundation of China, No.41571163; Northwest University Doctorate Dissertation of Excellence Funds, No.YYB17016

Author: Chen Jia, PhD Candidate, specialized in social-ecological system and regional sustainable development E-mail: dongdongbj2010@126.com

Corresponding author: Yang Xinjun, Professor, E-mail: yangxj@nwu.edu.cn 
the Loess Plateau region of China, drought, soil erosion and other disturbances cause the regional environment to be very fragile. However, with the development of a socio-economy and rapid urbanization, unreasonable land utilization and other disturbances introduced by human activities have made human-environmental conflicts a core problem restricting the sustainable development of the eco-environment and society in semi-arid regions. Therefore, researchers have focused on related issues, such as the ability of ecologically vulnerable areas to adapt to multiple disaster risks and the restoration of the eco-environment, which are mainly related to natural disaster assessment and prevention (Rosa et al., 2013; Wang et al., 2014; Xin et al., 2009), regional eco-environment regulation and sustainable development (Nguyen et al., 2014; Gómez-Ortiz et al., 2013; Li et al., 2003; Zhao et al., 2011), natural resources and land use evaluation (Sannwald et al., 2012), and environmental evolution (Stoetzel et al., 2017; Wang et al., 2002; Lin et al., 2001). Most research results put emphasis on application-oriented single-perspective analysis (Al-Kalbani et al., 2014), which separates the connections in the human-environmental system. Due to the influence of system theory, some scholars began to attach importance to regional system associations, and some studies of the vulnerability of economical-environmental systems and human-environmental relationship evolution have been performed (Lu et al., 2013; Tian et al., 2013; Perry et al., 2013; Liu et al., 2002). However, the studies ignore the inherent connectivity of human and natural environmental factors and the influence of multiple disturbances; thus, the validity of the evaluation results needs to be verified.

Compared to traditional studies of human-environmental relationships, vulnerability research, based on the social-ecological system theory (Holling, 2001), integrates various perspectives and analysis methods to assess risks, sensitivity, adaptation and resilience (Ciftcioglu, 2017; Sannwald et al., 2012; Nelson et al., 2007), and this work provides a new mode of thinking about human-environmental relationships (Speranza et al., 2014; Cumming et al., 2011; Turner et al., 2003). However, two difficulties still exist. On the one hand, the complex evaluation indexes, unsystematic data organization methods and lack of an inductive theoretical model for coordinating the different data, indicators and information are obstacles in the vulnerability assessment. On the other hand, the lack of spatial-temporal revolution of elements in the human-environmental system and the uncertainty of disturbance risk measurements hinder the application of the evaluation outcomes. In recent years, research focus has moved from effects to adaptation and resilience. Additionally, studies about the human-environmental system's vulnerability emphasizing cross-scale and multi-factor integration are gradually becoming valued by scholars (Yang et al., 2015; Shi et al., 2014; Polsky et al., 2007 Acosta-Michlik et al., 2008; Patterson et al., 2004). Considering theoretical frameworks, Vulnerability Scoping Diagram (VSD) and Agents' Differential Vulnerability (ADV) have been proposed by Polsky et al. (2007) and Acosta-Michlik et al. (2008). Polsky and Acosta-Michlik, respectively, to provide a clear and comprehensive assessment method of vulnerability through its multi-data organization, explicit vulnerability connotation and index system construction method. Considering methods, Frazier et al. (2014) developed the SERV model to improve the accuracy and spatial availability of vulnerability assessments and to solve uncertain and indistinct problems in the index construction. With a distinct index system as well as the integration of various indexes of the environment's multiple risks and factors, this model can improve our understanding of the spatial-temporal differences and characteristics of an social-ecological systems (SESs) vulner- 
ability. The American mathematician Yager R.R. constructed the Ordered Weighted Averaging (OWA) algorithm (Yager, 1988; Yager, 1996). The principle of the algorithm is to rearrange the spatial data according to the attribute value. Furthermore, depending on the aggregation of data criterion weight and order weight, the preference of different subjects (decision-making risks) is simulated under the linguistic quantification operator. The OWA assessment method presents decision-making differences owing to subjective weight error and difference values among index factors, and it reflects the decision makers' attitude with regard to avoiding risks in decision problems, which can reduce the subjective cognition of decision makers impacting evaluation results. This method is an effective means to construct future scenario simulations of a social-ecological system. Therefore, integrating systematic vulnerability based on evaluation and technical methods can be used to effectively understand the interactions and evolution of the coupled human-environmental system.

Yulin City is an ecologically vulnerable area in China and experiences serious problems related to drought, soil desertification and soil erosion. During the period of "the 12th Five-Year Plan" (2011-2015) and "the 11th Five-Year Plan" (2006-2010), the energy industry in Yulin City entered the rapid development stage, and urbanization accelerated markedly, leading to considerable transformations in the regional human-environmental relationships. Therefore, this study has chosen Yulin City as an example to measure its disaster exposure risks and vulnerabilities associated with human activities and data was collected on Yulin City at typical times during 2000-2015. Based on the SES theory and by applying the integration analysis framework of vulnerability and the SERV model, this research expresses the spatial-temporal dynamics of vulnerability from 2000 to 2015 in Yulin City. Moreover, this work simulates the future development scenario of the SES via OWA and can act as a reference to the relevant departments in terms of disaster warning and adaptation management.

\section{Study area}

The study area is located between $107^{\circ} 28^{\prime} \mathrm{E}-111^{\circ} 15^{\prime} \mathrm{E}$ and $36^{\circ} 57^{\prime} \mathrm{N}-39^{\circ} 34^{\prime} \mathrm{N}$. Yulin City, the

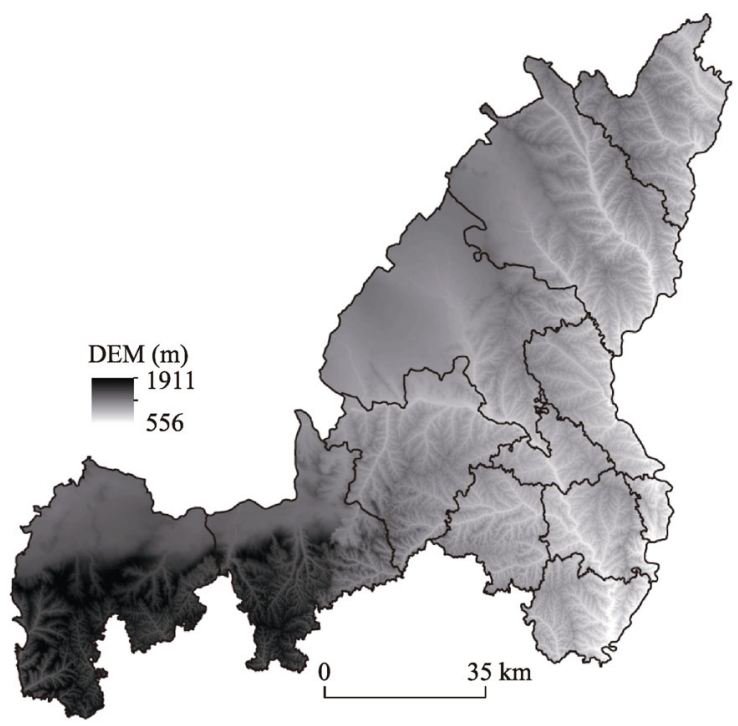

Figure 1 Location of the study area (Yulin City, Shaanxi Province, China) northernmost prefecture-level city in Shaanxi Province (Figure 1), is located at the juncture of the Loess Plateau and the southern margin of the $\mathrm{Mu}$ Us Sandy Land in a semi-arid region in China. Yulin City has 1 district and 11 counties, with a total population of 3.645 million, and land area of $43,578 \mathrm{~km}^{2}$. In terms of landforms, taking the Great Wall as a boundary, the northern parts are sandy areas, accounting for $42 \%$ of the total area, and the southern parts are a hilly-gully region, approximately $58 \%$ of the total area. The area features a temperate, semi-arid, continental monsoon climate, with four distinct seasons, short frost-free periods, an annual average 
temperature of $10^{\circ} \mathrm{C}$, an average precipitation of approximately $400 \mathrm{~mm}$ and a frost-free period of 150 days. Meteorological disasters, such as drought, hail and frost, are common. Moreover, the combination of hilly landforms composed of loess in the southern areas and the concentrated summer precipitation results in regional soil erosion and other serious ecological problems. Moreover, the regional energy and mineral resources include coal, oil, natural gas, rock salt and others, which have led to large-scale predatory energy exploitation since the late 1980s and caused eco-environmental damage in Yulin City. The advancement of urbanization, irrational land use and industrial economic developments have further aggravated the disturbance of social-ecological systems.

\section{Materials and methods}

\subsection{Theoretical structures and models}

Vulnerability is decomposed into three dimensions - exposure, sensitivity and adaptive capacity -to describe a social-ecological system. The basic idea of the VSD assessment framework is used to guide the whole process from data management to results simulation (Figure 2). Based on the indicators selection principles of SERV, this study constructs multiple factors and an explicit assessment index for quantitative evaluation of vulnerability and further selects proper indexes from the system corresponding to the actual habitat status at the county scale, as referenced from the Shaanxi Province and county almanac. Combining the SERV model and the RS/GIS spatial statistical analysis method, this study evaluates the vulnerability of the SES at the county scale, the spatial-temporal dynamic evolution and the shifting trends. Finally, the OWA algorithm is used to simulate the risks of the future system's vulnerability for different development scenarios in Yulin City, thus allowing evaluation results to be applied in regional practice.

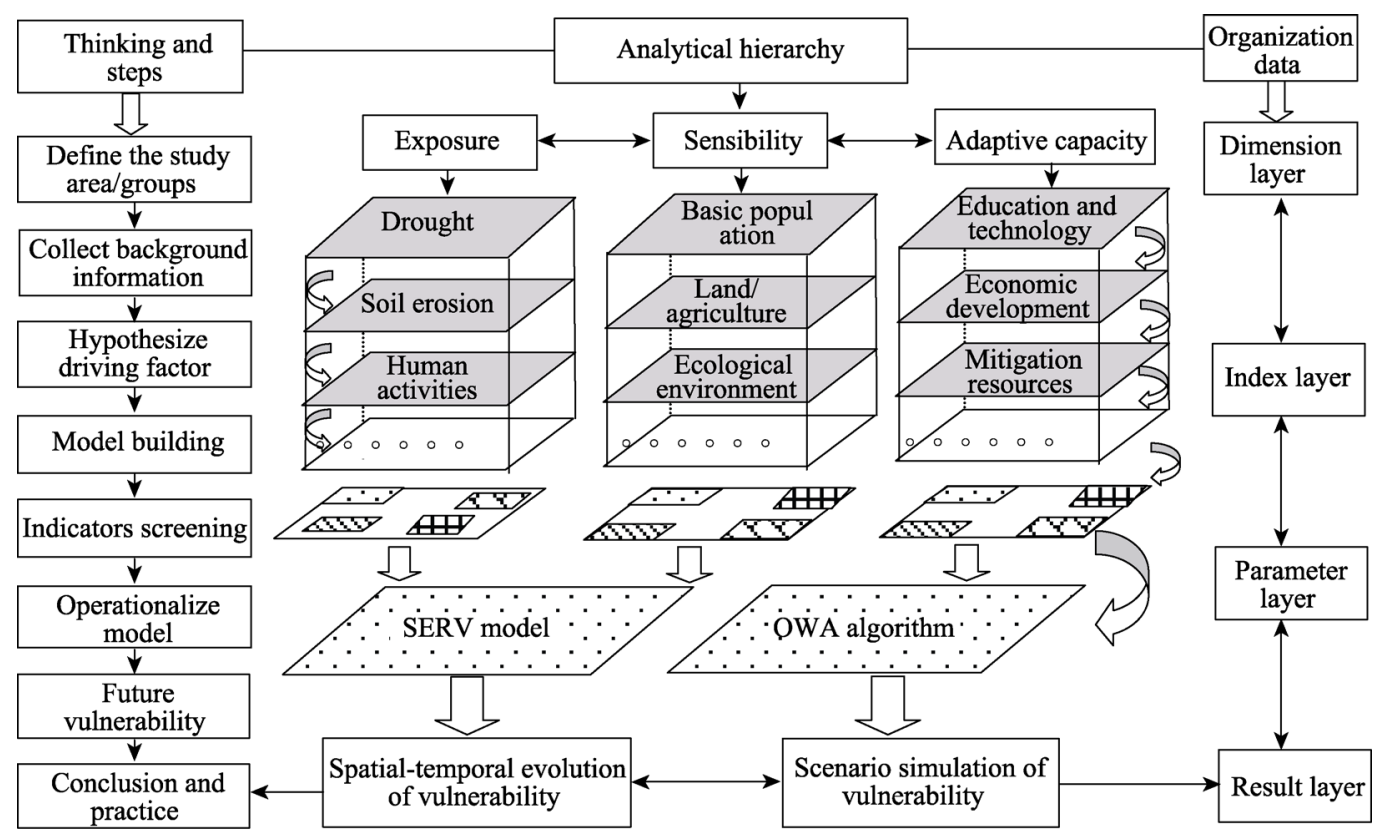

Figure 2 Ideas and methods of regional vulnerability assessment under the framework of VSD 


\subsubsection{VSD integration framework}

The theoretical structure of the vulnerability assessment is related to the whole study's cientific quality. By reviewing all the assessment theories and models proposed domestically and internationally, it can be observed that most focus on the causes and mechanisms of vulnerability and explore the inherent relationships among driving factors from different perspectives. However, the assessment framework for multiple factors and multiple risk disturbances at the regional scale is limited, and the VSD framework (Polsky et al., 2007) has made great achievements in many cases. VSD defines vulnerability as three dimensions exposure, sensitivity and adaptive capacity - and organizes the data using a progressive method of dimension layer-index layer-parameter layer, with eight steps of normative evaluation process (Figure 2). The deconstruction of the vulnerability assessment under this framework is in accord with the trend of integration analysis, and the clear evaluation process can guide the whole process from data processing to results application (Polsky et al., 2007; Huang et al., 2003).

\subsubsection{SERV vulnerability model}

To overcome limitations of previous vulnerability assessments, Frazier et al. (2014) proposed the SERV model, representing exposure (degree), sensitivity and adaptability through indexes related to the natural environment, social economy, spatial and local characteristics, which are used to evaluate regional vulnerability. This model serves to link theories to disaster risk research more directly. This model also incorporates local specific indicators into the evaluation index system, thereby differing from the previous general ways to organize data. As information provided by specific indicators in each county to reflect the local habitat status, this method solves the problem of the spatial distribution imbalance and dependence index. Simultaneously, due to the inherent connectivity of vulnerability factors, indicators expressing interactions among sensitivity and adaptability are emphasized. Moreover, SERV captures a key but overlooked point: vulnerable regions are not always in exposed regions; thus, the model suggests that limited resources should be allocated to more vulnerable regions, not just highly exposed areas, when developing adaptive strategies for regions (Frazier et al., 2014). The SERV model changes our way of thinking about assessing spatial vulnerability and helps to design targeted disaster reduction strategies, thus guiding the implementation. This model uses three elements for independent calculation, and its static vulnerability calculation equation is as follows:

$$
V=[E+S]-A C
$$

where $V$ represents the vulnerability, $E$ represents the exposure, $S$ represents the sensitivity, and $A C$ represents the adaptive capacity.

\subsection{Index system construction}

In the field of global environmental change, Adger (2006), Smit (2006), and Turner et al. (2003) generally agree that vulnerability refers to the sensitivity of a social-ecological system exposed to risk or to internal or external disturbances and a state in which the structure and the function of systems may be damaged due to the lack of adaptive capacity. Exposure, sensitivity and adaptive capacity are the three core components of system vulnerability (Turner et al., 2003; Roberts et al., 2003; Adger, 2006; Smit, 2006). Exposure refers to the 
degree of the external environmental pressure or risk disturbance and stress experienced by a system. Sensitivity is the extent to which exposed units are susceptible to being affected either positively or negatively. Adaptive capacity represents the self-regulating ability of the system in the face of risks and stress as well as the recovery potential in response to external interventions (adaptive management) (Chen et al., 2010). The higher the degrees of exposure and sensitivity, the higher the vulnerability of the social-ecological system, while the higher the adaptive capacity, the lower the vulnerability of the social-ecological system. Therefore, based on the VSD framework and the SERV model, this study links the natural environment, social economy and local specific indicators to disaster risks, thereby building an evaluation index system of social-ecological system vulnerability from the three dimensions of exposure, sensitivity and adaptive capacity (Tables 1 and 2).

\subsubsection{Exposure (risk) indicators}

The exposure risk in Yulin City is mainly caused by drought, soil erosion and human activities; hence, indicators of drought, soil erosion and human activities are considered with an analytic hierarchy process to determine the weight (Table 1). Drought risk is measured with a comprehensive drought state index, which combines hydrological drought (SRI) and meteorological drought (SPI) (Sun et al., 2014). The universal soil loss equation (USLE) is used for risk assessment of soil erosion (Zhang et al., 2011; Qin et al., 2009). Human activity disturbance is mainly due to the urbanization process and disturbances of the regional social

Table 1 Index system of exposure risk assessment

\begin{tabular}{|c|c|c|c|c|}
\hline $\begin{array}{l}\text { Dimen- } \\
\text { sion layer }\end{array}$ & $\begin{array}{l}\text { Element } \\
\text { type }\end{array}$ & Index layer & Weight & Indicator description and calculation \\
\hline \multirow{10}{*}{ Exposure } & Drought & Standardized precipitation & 0.2751 & \multirow{3}{*}{$\begin{array}{l}\text { SPI-SRI drought state model, combining the } \\
\text { meteorological and horological drought inde- } \\
\text { xes, adopting } 12 \text { months of data to reflect per- } \\
\text { iodic changes in the river water level and reservoir }\end{array}$} \\
\hline & $(0.4126)$ & $\begin{array}{l}\text { index (SPI) } \\
\text { Standardized runoff index } \\
(\mathrm{SRI})\end{array}$ & 0.1375 & \\
\hline & \multirow{3}{*}{$\begin{array}{l}\text { Soil } \\
\text { erosion } \\
(0.3275)\end{array}$} & Rainfall erosion $(\mathrm{R})$ & 0.0345 & \\
\hline & & Soil erodibility (K) & 0.0629 & \multirow{4}{*}{$\begin{array}{l}\text { Universal soil loss equation (USLE): } \\
A=R \times K \times L S \times C \times P \\
A \text { : Soil loss volume; } R \text { : Rainfall erosion; } \\
K \text { : Soil erodibility; } L S \text { : Length of slope; } \\
C \text { : Crop cover and management; } \\
P \text { : Soil and water conservation measures }\end{array}$} \\
\hline & & Length of slope (LS) & 0.0307 & \\
\hline & & $\begin{array}{l}\text { Crop cover and } \\
\text { management }(\mathrm{C})\end{array}$ & 0.0900 & \\
\hline & & $\begin{array}{l}\text { Soil and water conservation } \\
\text { measures }(\mathrm{P})\end{array}$ & 0.1095 & \\
\hline & \multirow{3}{*}{$\begin{array}{l}\text { Human } \\
\text { activities } \\
(0.2599)\end{array}$} & Urbanization rate (UB) & 0.1049 & \multirow{3}{*}{$\begin{array}{l}\text { Calculation formula of comprehensive land } \\
\text { use intensity (Wang et al., 2006): } \\
L_{x}=\sum_{i=n}^{4} A_{i} \times S_{i} / S \\
L_{x} \text { : Comprehensive index of land use degree in } \\
\text { the } x \text { th sample; } A_{i}: \text { Classification index of land } \\
\text { use grade } i ; S_{i}: \text { Land use area of grade } i ; S \text { : } \\
\text { Total land area of the sample area }\end{array}$} \\
\hline & & Land use intensity (LD) & 0.1550 & \\
\hline & & & & \\
\hline
\end{tabular}

\footnotetext{
Notes: (1) Drought, soil erosion and human activity indicators are positively related to exposure. (2) SPI and SRI were calculated by standardized precipitation index (SPI) formula from water regime of hydrology and water resources bureau of Yunnan province. (3) Precipitation erosion force factor (R), soil erodibility factor (K), and slope length factor (LS) data were from the National Earth System Science Data Sharing Infrastructure, and the data layer was generated via the spatial matching process. (4) Crop coverage and management factors (C) were estimated via the functional relationship between vegetation coverage $\mathrm{N}$ and vegetation coverage factor $\mathrm{C}$ : $\mathrm{C}=0.6508-0.3436 \operatorname{lgN}$. (5) By integrating the results of $\mathrm{Hu}$ Wenmin and Cai Chongfa and combining practical land use status in the study area to determine the values for the soil and water conservation measures factor $(\mathrm{p})$, the $\mathrm{p}$ values of different land use types were determined.
} 
ecosystem related to land use intensity. Finally, the three elements of exposure are processed with the weighted raster operation of ArcGIS to draw the regional exposure risk layer.

\subsubsection{Sensitivity/adaptive capacity index}

Jones and Andrey (2007) and Frazier et al., (2013) stated that there are different key factors of vulnerability in different research fields, locations and specific research scales. For example, the six counties of northern Yulin City are heavily reliant on the energy industry, and the county economic development is relatively better than that of the six agricultural counties of southern Yulin City, which are impoverished mountainous counties. Compared with the six counties in the south, indexes such as energy consumption and the number of employees employed in extractive industries are more likely to be the key factors of the sensitivity of the system in the northern six counties, while indexes such as the output value of major agricultural crops better represent the adaptive capacity (i.e., coping with vulnerability risk) of the six counties in the south. In addition, due to the vulnerability factors related to interaction and internal connectedness, the same factors affect the factors of sensitivity and adaptive capacity in different ways; for example, the forest area for soil conservation not only characterizes the sensitivity of soil erosion but is also an adaptive measure used to limit the risk of soil erosion. Therefore, through the existing literature research and reorganizing the data compiled in County Yearbooks over the years, this article summarizes the elements that have affected the sensitivity and adaptive capacity. In consideration of the actual situation in the study area, using the index selection principle of the SERV model, this research carefully screens the indexes to distinguish general and specific factors for different counties. Using this method, this study preliminarily constructs an index system of sensitivity and adaptive capacity for the counties in the study area. Additionally, this study adopts principal component analysis (PCA) to simplify and compress the relationships among a series of indexes in order to retain the significant variables for which the principal component load coefficient is $\leq-0.5$ or $\geq 0.5$. After screening, this study constructs the final indicators of sensitivity and adaptive capacity (Table 2), uses the variance contribution rate of the principal component analysis as the weight, and takes the principal components as variables to calculate the index layer of system sensitivity and adaptive capacity.

\subsection{Data sources and processing}

The data in this study mainly include remote sensing images and land use type captured in 2000, 2005, 2011, and 2015; meteorologic and hydrologic data (1954-1990 and 2002-2015); and Yulin City social statistics data (2000-2015). The remote sensing images of the study area are the products of the geospatial data cloud produced by the TM instruments aboard the Landsat 4 and 5 satellites, and these images were used to calculate and obtain the vegetation cover data in the study area in typical years. The land use data are from ten years of the Shaanxi provincial ecological database and were used to obtain data on land use intensity and soil conservation measures. The vector data of precipitation, runoff, slope, slope length and soil erosion factors are from the National Earth System Science Data Sharing Infrastructure. Population, environment, society, economic development and other indicators were calculated based on the original data from the Yulin City Statistical Yearbook (2000-2015).

\subsubsection{Data spatialization}

The spatial processing includes remote sensing data, precipitation/runoff data and statistical 
Table 2 Screening results of the sensitivity/adaptive capacity index

\begin{tabular}{|c|c|c|c|c|c|}
\hline $\begin{array}{l}\text { Dimen- } \\
\text { sion } \\
\text { layer }\end{array}$ & $\begin{array}{l}\text { Principal } \\
\text { component } \\
\text { factor }\end{array}$ & Universal index & $\begin{array}{l}\text { Index } \\
\text { proper- } \\
\text { ties }\end{array}$ & Specific index & $\begin{array}{c}\text { Index } \\
\text { pro- } \\
\text { perties }\end{array}$ \\
\hline \multirow{4}{*}{$\begin{array}{l}\text { Sensi- } \\
\text { tivity }\end{array}$} & $\begin{array}{l}\text { Basic popula- } \\
\text { tion principal } \\
\text { component }\end{array}$ & $\begin{array}{l}\text { The proportion of female population }(\%) \\
\text { The proportion of agricultural population (\%) } \\
\text { The proportion of employed population of agriculture, } \\
\text { forestry, animal husbandry and fishery (\%) } \\
\text { Natural population growth rate (\%o) } \\
\text { The average education level of labor (years) } \\
\text { Population density (people } / \mathrm{km}^{2} \text { ) }\end{array}$ & $\begin{array}{l}+ \\
* \\
- \\
+ \\
- \\
+\end{array}$ & $\begin{array}{l}\text { The number of } \\
\text { employees em- } \\
\text { ployed in extrac- } \\
\text { tive industry (peo- } \\
\text { ple) }\end{array}$ & $*$ \\
\hline & $\begin{array}{l}\text { Agriculture } \\
\text { and land } \\
\text { principal } \\
\text { component }\end{array}$ & $\begin{array}{l}\text { The proportion of cultivated land area }(\%) \\
\text { The proportion of paddy field/irrigated land area }(\%) \\
\text { The growth rate of housing construction area }(\%) \\
\text { The proportion of abandoned cultivated land area due } \\
\text { to disasters }(\%) \\
\text { Grain yield per unit area }(\mathrm{ha} / \mathrm{kg})\end{array}$ & $\begin{array}{l}* \\
* \\
+ \\
+ \\
-\end{array}$ & $\begin{array}{l}\text { Aquaculture area } \\
\text { (ha) } \\
\text { Main cash crop } \\
\text { yield (Chinese ju- } \\
\text { jube etc.) (tons) }\end{array}$ & - \\
\hline & $\begin{array}{c}\text { Ecology and } \\
\text { environment } \\
\text { principal } \\
\text { component }\end{array}$ & $\begin{array}{l}\text { Forest coverage }(\%) \\
\text { The proportion of effective irrigation area }(\%) \\
\text { Area of forest for water and soil conservation }\left(10^{3} \text { ha) }\right. \\
\text { Total energy consumption (tons of standard coal) }\end{array}$ & $\begin{array}{l}- \\
- \\
- \\
*\end{array}$ & $\begin{array}{l}\text { Total emission of } \\
\text { industrial } \\
\text { waste/waste water } \\
\left(10^{4} \text { tons }\right)\end{array}$ & + \\
\hline & $\begin{array}{c}\text { Economic } \\
\text { development } \\
\text { principal } \\
\text { component }\end{array}$ & $\begin{array}{l}\text { Per capita gross domestic product (yuan) } \\
\text { The proportion of total value of output of agriculture, } \\
\text { forestry, animal husbandry and fishery (\%) } \\
\text { Industrial structure dependence index } \\
\text { Engel's coefficient } \\
\text { Comprehensive energy consumption per unit GDP } \\
(10,000 \text { yuan/ tons of standard coal) }\end{array}$ & $\begin{array}{l}- \\
- \\
+ \\
+ \\
+\end{array}$ & $\begin{array}{l}\text { Industrial water } \\
\text { consumption per } \\
\text { unit GDP (tons } / 10^{4} \\
\text { yuan) }\end{array}$ & + \\
\hline \multirow{3}{*}{$\begin{array}{l}\text { Adap- } \\
\text { tive } \\
\text { capac- } \\
\text { ity }\end{array}$} & $\begin{array}{l}\text { Education } \\
\text { and technol- } \\
\text { ogy principal } \\
\text { component }\end{array}$ & $\begin{array}{l}\text { The number of teachers of per ten thousand people } \\
\text { possessed (people/ } 10,000 \text { people) } \\
\text { The proportion of students on campus (\%) } \\
\text { The number of communications equipment per } 100 \\
\text { households (telephone } / 100 \text { households) } \\
\text { Comprehensive utilization of product output value of } \\
\text { "three wastes" ( } 10^{4} \text { yuan) } \\
\text { The proportion of fiscal expenditure on education (\%) }\end{array}$ & $\begin{array}{l}+ \\
+ \\
+ \\
+ \\
+\end{array}$ & $\begin{array}{l}\text { The attainment rate } \\
\text { of the industrial } \\
\text { wastewater (\%) } \\
\text { Water saving irri- } \\
\text { gation machinery } \\
\text { (suits)/drainage and } \\
\text { irrigation power } \\
\text { machinery (kw) }\end{array}$ & + \\
\hline & $\begin{array}{l}\text { Social infra- } \\
\text { structure } \\
\text { principal } \\
\text { component }\end{array}$ & $\begin{array}{l}\text { The number of medical beds of per ten thousand people } \\
\text { possessed (people } / 10,000 \text { people) } \\
\text { The number of health service employees (people) } \\
\text { Fiscal expenditure on water affairs of agriculture and } \\
\text { forestry }\left(10^{4} \text { yuan) }\right. \\
\text { Social security expenditure per capita }\left(10^{4}\right. \\
\text { yuan/10,000 people) } \\
\text { The number of employees of transportation, storage } \\
\text { and postal service (people) }\end{array}$ & $\begin{array}{l}+ \\
+ \\
+ \\
+ \\
+\end{array}$ & 1 & \\
\hline & $\begin{array}{c}\text { Population } \\
\text { and economy } \\
\text { principal } \\
\text { component }\end{array}$ & $\begin{array}{l}\text { Per capita net income of farmers (yuan) } \\
\text { The density of social fixed assets investment }\left(10^{4}\right. \\
\left.\text { yuan/ } \mathrm{km}^{2}\right) \\
\text { The total output value of agriculture, forestry, animal } \\
\text { husbandry and fishery }\left(10^{4} \text { yuan }\right) \\
\text { The third industrial added value accounted for the } \\
\text { proportion of GDP }(\%) \\
\text { Local fiscal expenditure }\left(10^{4} \text { yuan }\right) \\
\text { Industrial structure diversification index }\end{array}$ & $\begin{array}{l}+ \\
+ \\
+ \\
+\end{array}$ & 1 & \\
\hline
\end{tabular}


(Continued)

\begin{tabular}{|c|c|c|c|c|c|}
\hline $\begin{array}{l}\text { Dimen- } \\
\text { sion layer }\end{array}$ & $\begin{array}{l}\text { Principal com- } \\
\text { ponent factor }\end{array}$ & Universal index & $\begin{array}{c}\text { Index } \\
\text { properties }\end{array}$ & Specific index & $\begin{array}{l}\text { Index } \\
\text { properties }\end{array}$ \\
\hline \multirow{5}{*}{$\begin{array}{l}\text { Adap- } \\
\text { tive ca- } \\
\text { pacity }\end{array}$} & \multirow{5}{*}{$\begin{array}{l}\text { Disaster pre- } \\
\text { vention and } \\
\text { mitigation fa- } \\
\text { cilities principal } \\
\text { component }\end{array}$} & Reservoir capacity $\left(10^{4} \mathrm{~m}^{3}\right)$ & + & \multirow[t]{5}{*}{ Dike length $(\mathrm{km})$} & \multirow[t]{5}{*}{+} \\
\hline & & The density of drought resistant infrastructure & + & & \\
\hline & & (number $/ \mathrm{km}^{2}$ ) & + & & \\
\hline & & Afforestation area in the year (ha) & & & \\
\hline & & $\begin{array}{l}\text { The area of forest for water and soil conserva- } \\
\text { tion (1000 ha) }\end{array}$ & & & \\
\hline
\end{tabular}

\begin{tabular}{llllllll}
\hline \multicolumn{2}{l}{$\begin{array}{l}\text { Results of sensitivity principal component } \\
\text { Years }\end{array}$} & \multicolumn{5}{l}{ Results of adaptive capacity principal component } \\
Minimum eigenvalue & 1.070 & 2005 & 2011 & Years & 2000 & 2005 & 2011 \\
Cumulative contribution rate & $91.94 \%$ & $90.75 \%$ & $89.99 \%$ & Cumulative contribution rate & $88.30 \%$ & $89.53 \%$ & $88.75 \%$
\end{tabular}

Notes: (1) Sensitivity and adaptive capacity: these two dimensions have no influence on each other. The detailed results of principal component analysis in each year are not listed here separately. "+" indicates that the indexes and the sensitivity or the adaptive capacity are positively correlated. "-" indicates that the indexes and the sensitivity or the adaptive capacity are negatively correlated. "*” indicates a moderate index, in which a certain value of the index value is the best. The moderate value is calculated from the standard mean value of indexes of each year in the study area. (2) The index system of the dimension of sensitivity and adaptive capacity is composed of universal indexes and specific indexes. Among them, the universal index is suitable for index factors of the whole region and the specific index reflects the index factor satisfying the actual habitat of each county. (3) The minimum eigenvalue means that principal component analysis of the index system in this year was used to extract the principal components with minimum eigenvalues. In Table 2, all the minimum eigenvalues are greater than 1, and the cumulative contribution rate is greater than $85 \%$, indicating that the extraction of the principal components is representative.

data. (1) The remote sensing data are based on Landsat 4-5 TM data, after using ERDAS software to process the original remote sensing images. The Mosaic Tool is adopted to synthesize three periods of remote sensing images for the study area. Modeling the band operation yields the NDVI data covering the study area, and using the mask extraction tool of ArcGIS provides the NDVI data for three typical years in Yulin City, which are used to calculate the vegetation coverage. (2) This research adopts the inverse distance weighted interpolation method for point source data, such as precipitation and runoff, in order to achieve spatial deterministic interpolation and spatialization. (3) For attribute data without $\mathrm{X}$ and $\mathrm{Y}$ coordinates, such as social statistics, this research uses ArcGIS software to input the attribute data into an attribute list for the administrative division vector in the study area, thereby achieving the spatialization of the data attributes. This study takes a grid as the basic research unit in order to ensure the agreement between the indexes and the spatial locations. We define the spatial data grid size as $30 \mathrm{~m} \times 30 \mathrm{~m}$, and the spatial data are fit to the grid using unified Krasovsky ellipsoidal coordinates and Albers projection.

\subsubsection{Data standardization}

To eliminate the problem of inconsistent dimensions in the index data, this research standardizes the original data of the social statistics. Considering that the positive and negative indicators of vulnerability assessment have different effects on the vulnerability of the system, different standardization methods are adopted. The range standardized method is applied to the positive and negative indicators. For the moderate indexes (that is, the indexes in which moderate values are the best) with a certain ambiguity, this study adopts the method of fuzzy membership function based on the work of the American scholar L.A. Zadeh for non-dimensional processing (Duan, 2005). 


\subsection{Analytical methods}

\subsubsection{Variation slope method}

Using the variation slope method to calculate the change in the slope of vulnerability for each grid pixel, this research performs a regression simulation between the vulnerability indexes of the social-ecological system of Yulin City during 2000-2015 and time in order to express the variation trend of regional vulnerability over 16 years. The variation slope is positive, which indicates that the vulnerability of the region shows an increasing trend. In contrast, a negative value would indicate that the vulnerability of the region shows a decreasing trend. The specific calculation formula of the slope variation is as follows (Chen et al., 2008):

$$
X_{\text {slope }}=\frac{n \times \sum_{i=1}^{n} i \times S E S S V I_{i}-\left(\sum_{i=1}^{n} i\right)\left(\sum_{i=1}^{n} S E S S V I_{i}\right)}{n \times \sum_{i=1}^{n} i^{2}-\left(\sum_{i=1}^{n} i\right)^{2}}
$$

where $n$ represents the year; SESSVI represents the vulnerability index of the $i$ th pixel in the raster data; $X_{\text {slope }}$ represents the variation slope of the grid pixels and the degree of long-term changes in regional vulnerability. The $F$ test is used to test the significance of the variation slope and is calculated as follows:

$$
F=U / \frac{Q}{n-2}
$$

where $Q=\sum_{i=1}^{n}\left(Y_{i}-\hat{Y}\right)^{2}$ is the error sum of squares; $U=\sum_{i=1}^{n}(\hat{Y}-\bar{Y})^{2}$ is the regression sum of squares. $Y_{i}$ is the actual value of SESSVI of the $i$ th year, and $\hat{Y}$ is its regression value; $\bar{Y}$ is the average value of each year. According to the calculation of the variation slope and the $F$ value significant test, the results can be divided into three categories: significant increase $\left(X_{\text {slope }}>0, P<0.05\right)$, significant decrease $\left(X_{\text {slope }}<0, P<0.05\right)$, and no significant change $(P>0.05)$.

\subsubsection{OWA analytical method}

The Ordered Weighted Averaging (OWA) algorithm is a method based on the ordered weighted mean, and the core of this method involves calculating the criterion weight and order weight of spatial index data. By adjusting the size of the decision risk among the transformation of logical operations, the OWA algorithm obtains results for different risk evaluations. It uses the AHP method to determine the weight of each index, while determining the order weight has various methods. This study adopts the fuzzy quantification model first proposed by Yager, as this model is simple, easy to understand, and widely used (Yager, 1988, 1996). The specific formula is as follows:

$$
v_{j}=\left(\sum_{k=1}^{j} w_{k}\right)^{a}-\left(\sum_{k=1}^{j-1} w_{k}\right)^{a} a \in(0-\infty),(j=1,2,3, \ldots, n)
$$

where $V_{j}$ represents order weight; $a$ is the decision risk coefficient, which depends on the 
degree of optimism of the decision maker facing decision risks; and $W_{k}$ represents the importance degree of the index, which can be calculated with formula (8):

$$
w_{k}=\frac{n-r_{k}+1}{\sum_{I=1}^{k}\left(n-r_{I}+1\right)}(k=1,2,3, \ldots, n)
$$

where $n$ is index number, and $r_{k}$ represents the assignment of the index importance according to the index value, for which the maximum value is 1 , the second largest value is 2 , and the minimum value is $n$.

\section{Result analysis}

\subsection{Exposure risk analysis}

According to the specific exposure risk type in the study area, this research adopts the ArcGIS raster calculator to perform the weighted operation. The results are shown in Figure 3. The risk exposure from 2000-2015 in the study area formed a pattern approximately characterized by high values in the northwest and low values in the southeast. The pattern after 2005 featured low values in the middle and southern parts and high values in the northern. The area of high exposure risk first increased then decreased from 2000-2015 and is mainly concentrated in Shenmu County, Fugu County and Yuyang District, all of which have dense populations, developed industries, and high-intensity land development. The low exposure risk area is concentrated along the Great Wall (400-450 $\mathrm{mm}$ precipitation line) and the southern region.

The high-intensity areas of soil erosion are concentrated in the eastern and southwestern regions in Yulin City, while the distribution pattern of drought decreases from the southeast to the northwest. Based on the spatial evolution pattern of the exposure risk in Yulin City over the 16 years (see Figure 3), it is known that the spatial distribution of exposure risk is roughly similar to those of drought and high-intensity human activity. Therefore, the drought and the disturbance due to human activities may be the main influencing factors for the regional exposure risk. However, in recent years, with the implementation of soil conservation measures, such as returning farmland to forest (grass) and comprehensive management of small watersheds, the impact of soil erosion risk has begun to weaken, and the southern ecological condition has clearly gotten better. These trends show that the risk source of exposure is uncertain and complex and includes a reduction in the self-adjustment ability (or sensitivity threshold) of the exposed units, which highlights the potential problems, and constant changes in the type and number of its exposure factors. On the whole, the role of regional topography, climate, hydrology, vegetation and other special natural geographical factors, as well as human activities in ecological system, together determine the spatial distribution characteristics of exposure risk in Yulin City.

\subsection{Spatial-temporal evolution of vulnerability of social-ecological system}

\subsubsection{Spatial-temporal distribution characteristics of vulnerability}

On the basis of overlaying the index layers of the exposure, sensitivity and adaptive capacity 
(a) 2000

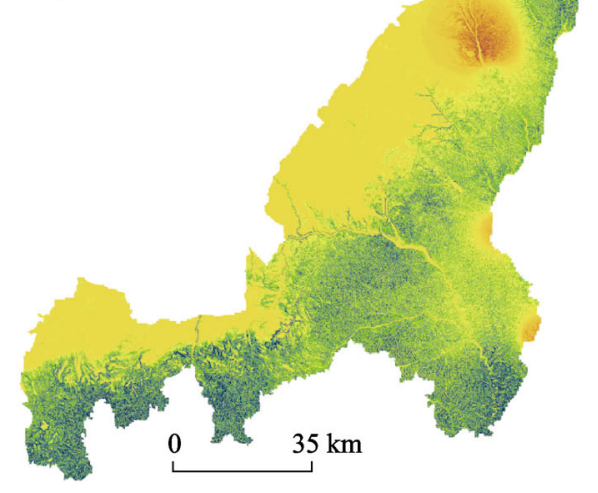

(c) 2011

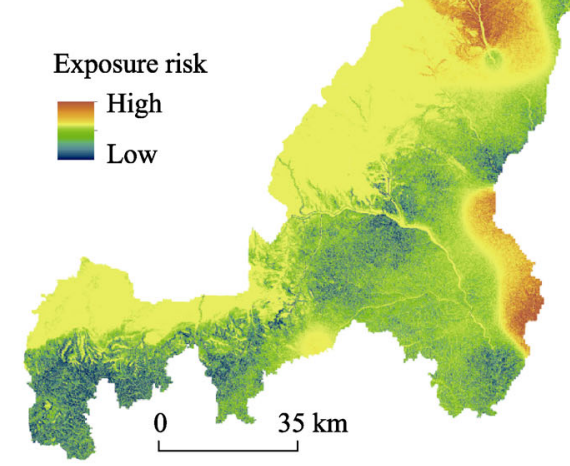

(b) 2005

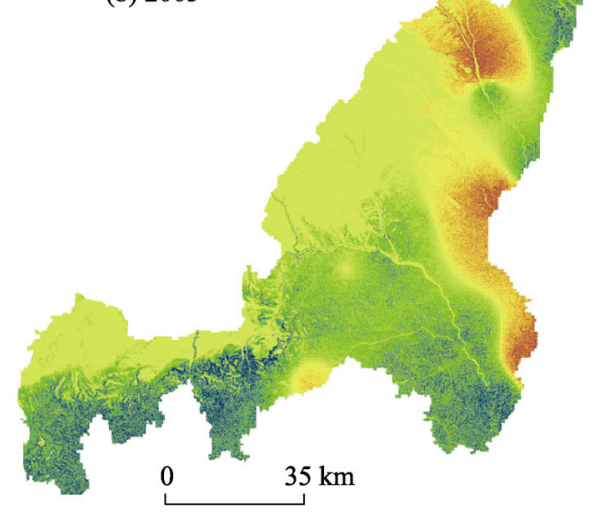

(d) 2015

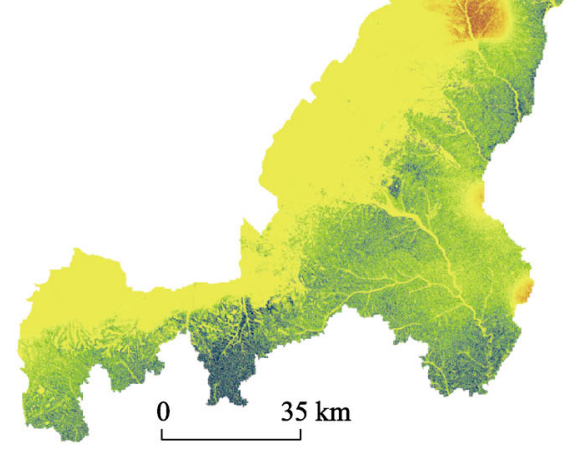

Figure 3 The spatial framework of exposure risk in Yulin City during 2000-2015

(derived from the calculation results of the static vulnerability equations of SERV model and the natural breakpoint method), this study divides vulnerability into five categories that represent areas of low vulnerability, low-medium vulnerability, medium vulnerability, medium-high vulnerability and high vulnerability. As shown in Figure 4, the overall vulnerability of the social-ecological system corresponds to the medium level during 2000-2015 in Yulin City. The spatial pattern of the vulnerability can be characterized as "high in northwest and southeast and low along the Great Wall", and medium- and high-vulnerability areas show a decreasing trend. Meanwhile, there is a significant difference in the spatial-temporal distribution of vulnerability. In 2000, the area of the high-vulnerability region is larger than those of 2005, 2010 and 2015. The high-vulnerability region of the study area has been mainly concentrated in the core area of the northern cities and energy bases for 16 years. The medium-vulnerability area is mostly located near the northwest of the Mu Us Desert, while the low-vulnerability area is located along the Great Wall and the junction of the northern six counties and the southern six counties.

In the time dimension, the overall vulnerability of social-ecological system shows a decreasing trend in the study area during 2000-2015. The proportion of the area with vulnerability levels above medium decreases from $66.587 \%$ to $57.103 \%$ (see Table 3 ). In 2000 , the area of high vulnerability and medium-high vulnerability is $478.83 \mathrm{~km}^{2}$ and $7023.29 \mathrm{~km}^{2}$, 
respectively, while the area of medium-high vulnerability region is only $245.344 \mathrm{~km}^{2}$ in 2015. From the point of view of the regionally dominant vulnerability level, the proportions of the area of medium vulnerability are $49.37 \%$ and 57.83\% in 2000 and 2005, which shows that half of Yulin City experiences some vulnerability. In 2011 and 2015, the dominant level of vulnerability is the low-medium level, accounting for $45.86 \%$ and $39.80 \%$ of the regional land area, respectively. This pattern indicates that the regional social-ecological system is developing towards a good situation.

In the spatial dimension, the spatial variation of vulnerability in the study area shows a southward trend in terms of low vulnerability region over the 16 years. The distribution of the medium-vulnerability area has a relatively large fluctuation, and the northwest-southeast distribution pattern evolves into a primary concentration in the northwest. The high-vunearility region gradually decreases, and it is mainly concentrated in the northern Shenmu-Fugu counties in 2000-2011 and is absent in 2015. Comparing the data of land use types in the study area during 2000-2011, it is found that there is a consistency between the high-vulnerability area and the spatial distribution of the mining area. Shenmu and Fugu counties are an important energy base in China. Mines are densely distributed in this area, resulting in unrecoverable damage to the ecological environment. Excessive exploitation of energy and extensive economic development further exacerbates the vulnerability of a social-ecological system.

\subsubsection{Analysis of the trend of vulnerability evolution}

According to the variation slope method and the results of the significance test (Figure 5), in the period of 2000-2015 in Yulin City, the slope of the overall vulnerability change is negative accounted for more than $96 \%$ of the pixels, and the area of reduced vulnerability is dominant, which further explains the gradual improvement in the regional social-ecological system over the past 16 years.

From the left and right graphs in Figure 5, we can see that the pixels with significantly reduced vulnerability trends $(p<0.05)$ are concentrated in areas of high and medium vulnerability. These regions are sparsely populated areas in five counties in the northwest and south. The areas where the slope of the change is significantly higher than 0 are distributed along the low-vulnerability Great Wall region. The main reason is that the medium- and high-vulnerability areas are related to soil erosion, northwestern sandstorms and intensive energy development. Due to the effects of soil conservation, returning farmland to forest, shelter forest development and other policy measures, coupled with the decline of the traditional energy economy in recent years, the transformation of the economic structure (driven by the energy resource depletion crisis) has promoted the gradual restoration of the regional eco-environmental system. Thus, the degree of vulnerability in such areas has been reduced. However, this pattern does not show that the vulnerability of the social-ecological system in such areas is lower than other low-vulnerability areas; it only shows that the trend of changes has improved. According to the comparative analysis in Figures 4 and 5, the trend of vulnerability change in medium- and high-vulnerability areas fluctuates greatly but that a significant reduction occurred over the 16 years (Figure $5 \mathrm{~b}$ ). In essence, the high-risk areas of the social-ecological system are still concentrated in the northern (or northwestern) counties that are densely populated and exhibit good economic conditions. However, to a certain 
extent, the evolution trend over 16 years shows that the previous high-vulnerability area of the social-ecological system in Yulin City has decreased and that the overall system at this stage has a good development trend.

(a) 2000

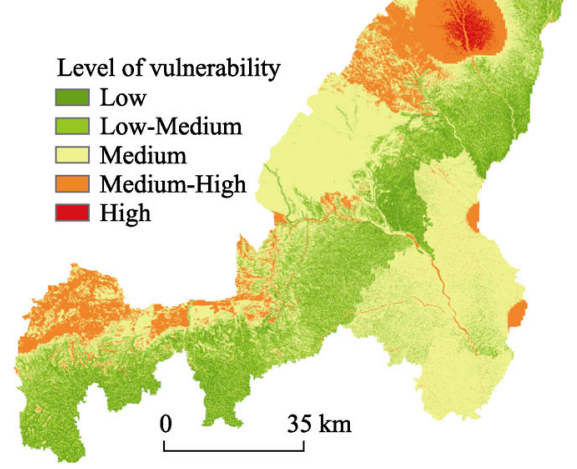

(c) 2011

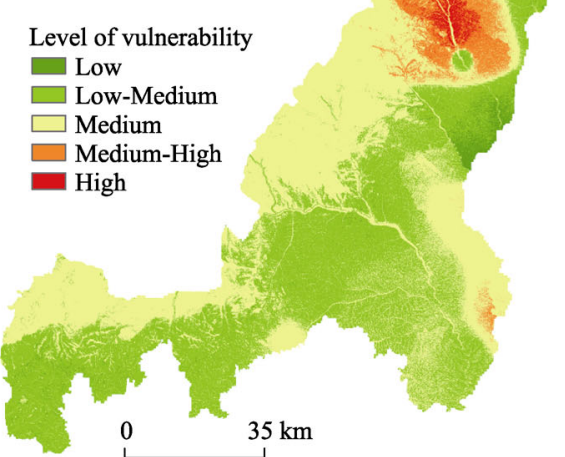

(b) 2005

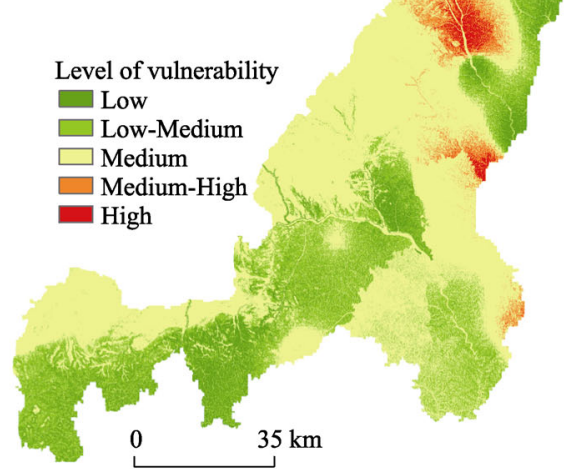

(d) 2015
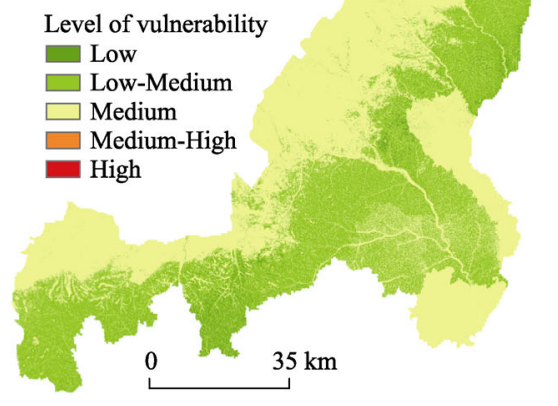

Figure 4 Spatial-temporal distribution of the vulnerability of social-ecological systems (SESs) in Yulin City during 2000-2015

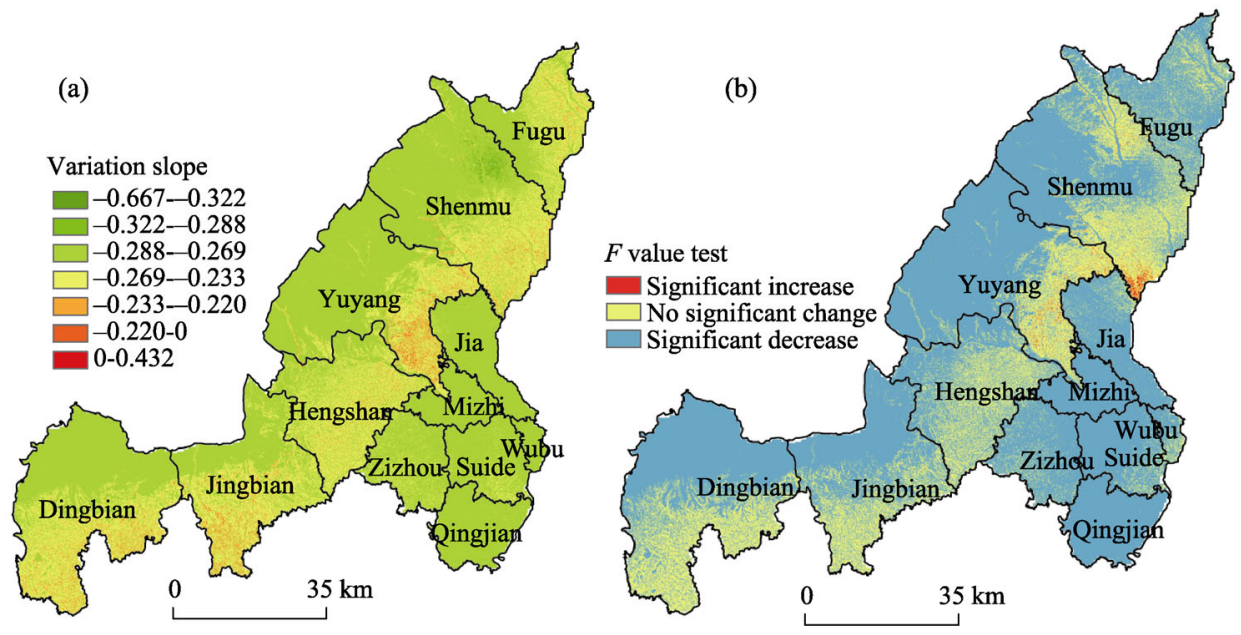

Figure 5 SES vulnerability variation trend (a) and F test (b) in Yulin City during 2000-2015 
Table 3 Classification of social-ecological system vulnerability in the study area during 2000-2015

\begin{tabular}{|c|c|c|c|c|c|c|c|}
\hline \multicolumn{2}{|c|}{ Year / Type } & $\begin{array}{l}\text { High vul- } \\
\text { nerability }\end{array}$ & $\begin{array}{l}\text { Medium-high } \\
\text { vulnerability }\end{array}$ & $\begin{array}{c}\text { Medium } \\
\text { vulnerability }\end{array}$ & $\begin{array}{l}\text { Low-medium } \\
\text { vulnerability }\end{array}$ & $\begin{array}{c}\text { Low } \\
\text { vulnerability }\end{array}$ & $\begin{array}{l}\text { Above medium } \\
\text { vulnerability }\end{array}$ \\
\hline \multirow{2}{*}{2000} & Proportion/\% & 1.098 & 16.116 & $\underline{49.373}$ & 21.459 & 11.951 & $\underline{66.587}$ \\
\hline & Area $/ \mathrm{km}^{2}$ & $\underline{478.836}$ & 7023.390 & 21515.901 & 9351.638 & 5208.232 & 29018.127 \\
\hline \multirow{2}{*}{2005} & Proportion/\% & 1.791 & 2.679 & $\underline{57.833}$ & 25.471 & 12.224 & 62.303 \\
\hline & Area $/ \mathrm{km}^{2}$ & 780.551 & 1167.519 & 25202.816 & 11099.949 & 5327.163 & 27150.886 \\
\hline \multirow{2}{*}{2011} & Proportion/\% & 1.460 & 5.644 & 44.871 & $\underline{45.863}$ & 2.160 & $\underline{51.975}$ \\
\hline & Area $/ \mathrm{km}^{2}$ & 636.319 & 2459.650 & 19553.933 & 19986.428 & 941.6683 & 22649.902 \\
\hline \multirow{2}{*}{2015} & Proportion/\% & 0.0009 & 0.563 & 56.540 & 39.800 & 2.997 & $\underline{57.103}$ \\
\hline & Area $/ \mathrm{km}^{2}$ & $\underline{0.414}$ & 245.344 & 24682.578 & 17344.043 & 1306.033 & 24928.336 \\
\hline
\end{tabular}

\subsection{Spatial-temporal heterogeneity between the vulnerability and exposure risk}

There are spatial distribution differences between the areas with higher vulnerability and the areas with higher exposure risk, but this spatial heterogeneity is often overlooked in most studies. The evaluation of the SERV model advocates allocating limited resources to more vulnerable areas rather than just highly exposed areas, as less exposed but vulnerable areas are often more sensitive to disaster risks. Therefore, a comprehensive vulnerability assessment should focus on the spatial heterogeneity between exposure risk and vulnerability. In this study, vectorization of the grid data of the exposure risk assessment and the results of the spatial-temporal vulnerability evolution and the intersection tool of the overlay analysis were used to obtain a spatial heterogeneity maps of exposure risk and vulnerability levels in 2000, 2005, 2011 and 2015 (Figure 6).

As shown in Figure 6, from 2000-2015, the low exposed-vulnerable areas in Yulin City are mainly distributed in the less developed areas in the south, and the area of spatial heterogeneity gradually decreases over time but is concentrated in the hilly and gully areas of the southeastern part. Under the condition of low exposure risk, the situation of medium-high vulnerability is bound to reflect the state of high sensitivity and low adaptive capacity in terms of risks. There are five counties to the south of the Great Wall, where the development of traditional agriculture is limited by natural terrain, water resources and limited arable land area, coupled with lagging infrastructure construction and the lack of energy resources. In recent years, the socio-economic development of these regions has lagged far behind that of the northern energy-rich counties, resulting in a low adaptive capacity in the system. Secondly, the regional population density of Yulin City is basically high in the southeast and low in the northwest. The southern counties contain large farmlands and convenient valley roads, resulting in a higher population density. Therefore, the social sensitivity of such areas in the event of a disaster is higher.

Over the past ten years, the population of the southern counties of Yulin City has moved north or settled outside of rural settlements, resulting in the hollowing out of rural settlements and the abandonment of cultivated land, thereby reducing the impact of human activities on the local areas. This phenomenon is beneficial to the restoration of the ecosystem and the reduction of the disaster exposure, but the development of social systems is unbalanced, 

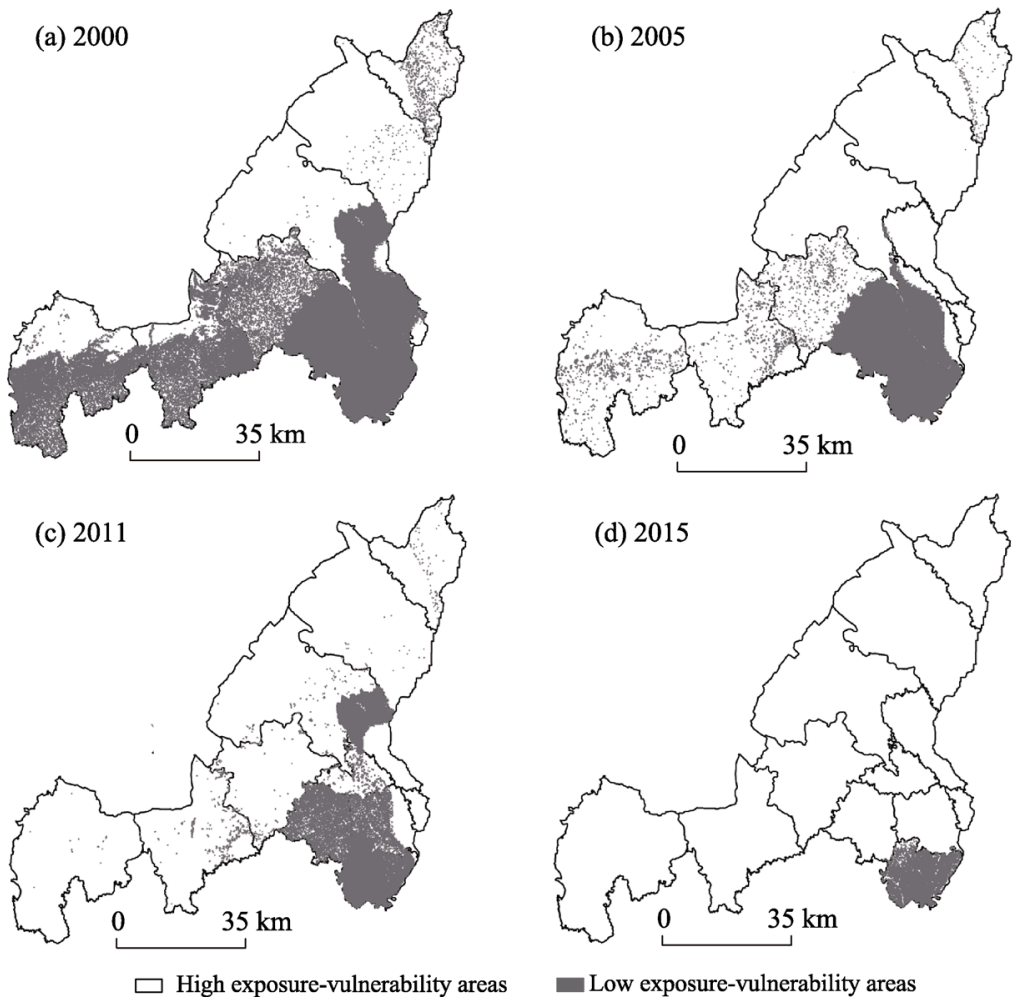

Figure 6 The spatial heterogeneity of SESs vulnerability and exposure risk in Yulin City during 2000-2015

and the potential vulnerability increases. Therefore, to reduce the vulnerability in southern counties, it is important to increase the investment of resources in low exposure-vulnerability areas, to promote the transformation to a modern agricultural economy, and to enhance the development of capacity with social infrastructure, such as education and technology, disaster prevention and mitigation.

\subsection{Vulnerability scenario simulation}

The principle of the OWA algorithm, based on the calculation of order weight and criterion weight, is used to obtain a comprehensive evaluation chart of the regional social-ecological system vulnerability by incorporating different factors affecting the vulnerability. Through the setting of different decision risk coefficients, the regional system vulnerability is simulated, generating multiple scenes. The decision-making risk coefficient $(a)$ reflects the optimism of the decision maker on issues, the value of the coefficient $a$ ranges from 0 to infinity, corresponding to a range from optimism to pessimism. When $a=1$, the attitude of the decision maker is neutral, and the order weights are equal. The OWA algorithm then overlays the traditional criterion weight layer, and the regional system vulnerability corresponds to the status quo. In the case of $a>1$, the decision maker is pessimistic about the vulnerability of the regional system and believes that there is a high exposure risk in the region and that the significantly increasing vulnerability is harmful to the sustainable development of regional social-ecological system. On the contrary, if $a<1$, the decision maker is optimistic and believes that the risk of regional vulnerability is manageable or in control and that it does not affect the stable development of the regional social-ecological system. 


\subsubsection{Scenario index formulation and analysis}

The design of the vulnerability scenario index is based on the existing evaluation index system (Tables 1 and 2) and involves integrating and selecting the indexes of exposure risk, sensitivity and adaptive capacity and removing the factors that are complex and that have small loading coefficients. The exposure risk index layer remains unchanged, whereas the top 3 indexes are selected for the indicators of sensitivity and adaptive capacity based on the closeness of the relationship to each principal component. There are 11 scenarios in total, and the weight was determined based on the analytic hierarchy process. Sensitivity indexes include the layers of population, land, ecology and economy; adaptive capacity indexes include the layers of environment and technology, social resources, economic development, disaster prevention and mitigation resource.

To obtain the final results, the order weight of the scene index layer was calculated according to the formulas (4) and (5) (Table 4). The grid index layer was standardized and assigned in ArcGIS 10.0, and the criteria weight and order weight of different decision risk coefficients $^{1}$ were input to calculate the OWA module of multi-criteria evaluation (MCE) in IDRISI 17.0 (Figure 7).

According to the natural breakpoint method, the regional vulnerability grid layers of different decision risk assessments are divided into five categories, which represent low, low-medium, medium, medium-high and high vulnerability. As shown in Figure 7, when the decision maker is extremely optimistic to just optimistic ( $a=0.001$ or 0.1$)$, the whole area is basically in a low-vulnerability situation, but the decision-making risk is the highest and is not in line with the actual situation. When the decision maker is relatively optimistic $(a=0.5)$, the majority of the area exhibits low vulnerability, and the northern part has a trend in which

Table 4 Results of the ordered weight

\begin{tabular}{|c|c|c|c|c|c|c|c|c|}
\hline $\begin{array}{r}\text { De } \\
\text { Decis }\end{array}$ & $\begin{array}{l}\text { ion risk coefficient } \\
\text { n-maker's risk attitude }\end{array}$ & $\begin{array}{l}\mathrm{a}=0.0001 \\
\text { Extremely } \\
\text { optimistic }\end{array}$ & $\begin{array}{l}\mathrm{a}=0.1 \\
\text { Opti- } \\
\text { mistic }\end{array}$ & $\begin{array}{l}\quad \mathrm{a}=0.5 \\
\text { Relatively } \\
\text { optimistic }\end{array}$ & $\begin{array}{l}\quad \mathrm{a}=1 \\
\text { Unbiased } \\
\text { represen- }\end{array}$ & $\begin{array}{l}\quad \mathrm{a}=2 \\
\text { Relatively } \\
\text { pessimis- }\end{array}$ & $\begin{array}{c}\mathrm{a}=10 \\
\text { Pessimis- } \\
\text { tic }\end{array}$ & $\begin{array}{c}\mathrm{a}=1000 \\
\text { Extremely } \\
\text { pessimistic }\end{array}$ \\
\hline & $\begin{array}{l}\text { Environment and } \\
\text { technology }\end{array}$ & 1.000 & 0.786 & 0.301 & 0.090 & 0.008 & 0.000 & 0.000 \\
\hline & Social resources & 0.000 & 0.056 & 0.124 & 0.090 & 0.024 & 0.000 & 0.000 \\
\hline & Economic development & 0.000 & 0.034 & 0.095 & 0.090 & 0.041 & 0.000 & 0.000 \\
\hline & $\begin{array}{l}\text { Disaster prevention and } \\
\text { mitigation resources }\end{array}$ & 0.000 & 0.025 & 0.080 & 0.090 & 0.057 & 0.000 & 0.000 \\
\hline OWA & Basic population & 0.000 & 0.020 & 0.071 & 0.090 & 0.074 & 0.000 & 0.000 \\
\hline $\begin{array}{l}\text { Order } \\
\text { weight }\end{array}$ & Land and agriculture & 0.000 & 0.017 & 0.064 & 0.090 & 0.090 & 0.002 & 0.000 \\
\hline & Ecosystem & 0.000 & 0.014 & 0.059 & 0.090 & 0.107 & 0.008 & 0.000 \\
\hline & Economic resources & 0.000 & 0.012 & 0.055 & 0.090 & 0.124 & 0.030 & 0.000 \\
\hline & Drought & 0.000 & 0.011 & 0.051 & 0.090 & 0.140 & 0.093 & 0.000 \\
\hline & Soil erosion & 0.000 & 0.010 & 0.048 & 0.090 & 0.157 & 0.251 & 0.000 \\
\hline & Human activity & 0.000 & 0.009 & 0.046 & 0.090 & 0.173 & 0.614 & 1.000 \\
\hline
\end{tabular}

1 The decision risk coefficient is chosen according to the typical parameters in the OWA operator - $a$ corresponds to $0.001,0.1,0.5,1,2,10$, and 1000 - to express decision-making attitudes of decision makers from optimistic to pessimistic. 


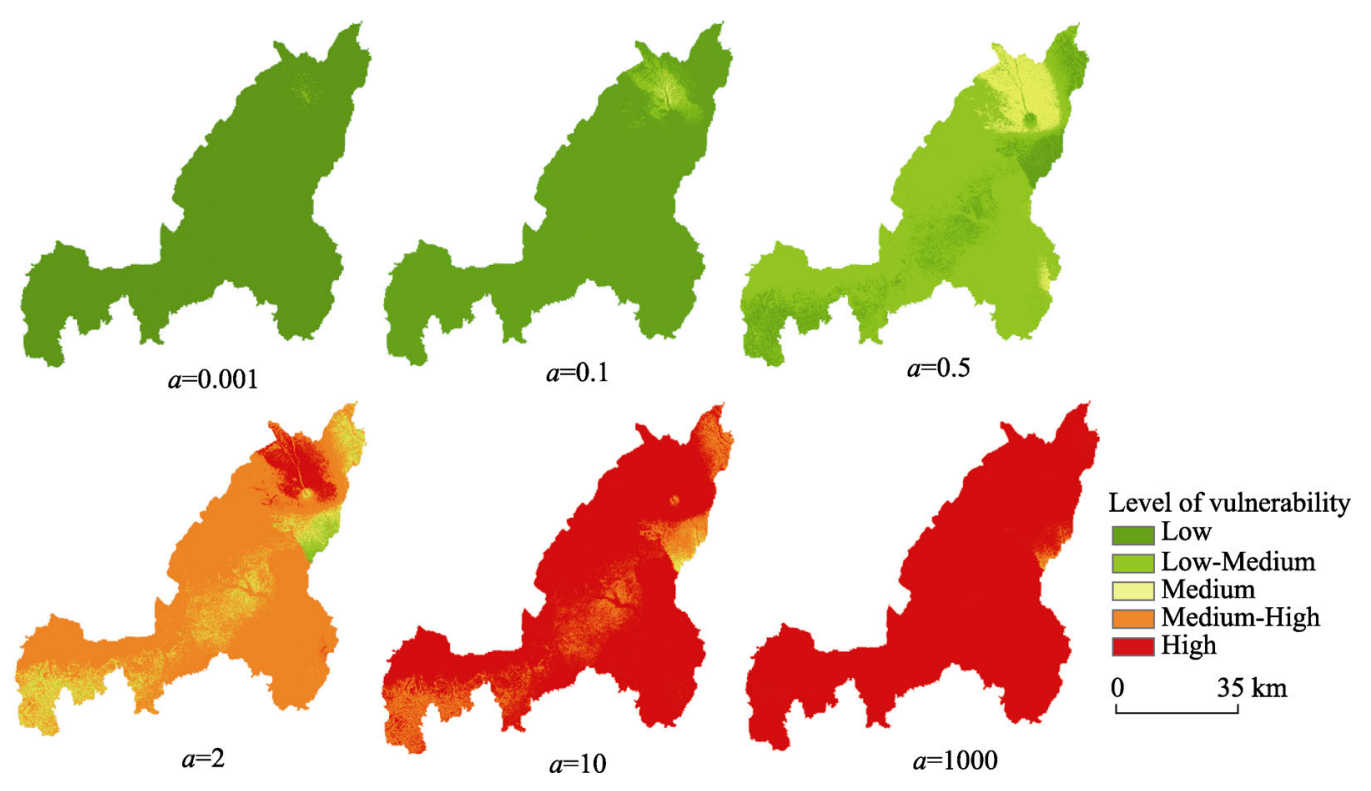

Figure 7 The simulation results of the vulnerability of social-ecological systems (SESs) in decision-making risk

the vulnerability increases to a certain extent. When the decision maker is relatively pessimistic, the majority of the area exhibits a high degree of vulnerability, and some economically developed areas in the north exhibit high vulnerability. For the decision maker to decrease the risk, the influence of the order weight on the final evaluation result of the evaluation unit increases, which leads an increase in the maximum vulnerability. Therefore, when the decision maker is pessimistic to extremely pessimistic ( $a=10$ or 1000), the social-ecological system of the study area is in a highly vulnerable state, and the decision risk is minimal but is divorced from rational reality. The analysis of the results for different decision-making risk levels can dynamically show the spatial evolution process of the vulnerability level of the social-ecological system in the study area. Moreover, it can simulate the influences of risk-cognitive behaviors of decision makers on system vulnerability changes, which provides decision references for the scenario prediction of system vulnerability.

\subsubsection{System vulnerability scenario settings}

Based on the dynamic simulation of different decision-making risk levels and considering the rational reality, decision makers often need to assess scientific arguments and trade-offs for the regional development planning and policy formulation. The results of extreme decision-making are not in line with the actual situation. The economic development of the energy industry has been a "double-edged sword" in Yulin City since "the 10th Five-Year Plan" (2001-2005). There is a trade-off relationship between socio-economic development and ecological environment protection in the formulation of development policies. After "the 12th Five-Year Plan" (2011-2015), the energy industry faces the "resources trap", and the focus of the policy set has turned to the transformation of the economic development structure and the implementation of sustainable development. Therefore, based on the investigation of the socio-economic development strategy and the present situation of Yulin City, 
three types of possible policy behaviors ${ }^{2}$ are proposed: the status quo type, the economic priority type, and the sustainability-oriented type. The social-ecological system vulnerability under these three scenarios was simulated and evaluated.

Considering the complexity of the influencing factors of vulnerability in the social-ecological system, the relationships among factors is uncertain, and the decision-making risk range $(0.5<a<2)$ satisfying most index factors represents a more realistic scenario simulation. Therefore, based on the range of the normal decision risk coefficient and the rational thinking of decision makers, $a=1$ corresponds to maintaining the status quo type, which represents the normal weighting operation results under the existing disaster risk, regional sensitivity and adaptive capacity. Similarly, the decision risk coefficient $a=[0.5,2]$ interval is further refined and simulated. Considering the small fluctuations in decision makers' subjective rational ranges and based on previous research results, the decision risk coefficients $a=0.8$ and $a=1.2$ are taken as the credible fluctuation interval nodes that are established under the current risk decision coefficient. Among them, $a=0.8$ indicates that the exposure risk is controlled, and the system vulnerability is low, which is defined as an optimistic decision-making scenario of sustainable development orientation. The value $a=1.2$ means the disaster risk is difficult to control, which is a pessimistic decision-making scenario of economic development priority.

In Figure 8, it can be observed that the spatial distributions of the "the status quo type" scenario and the vulnerability of the social-ecological system of Yulin City in 2011 are similar, indicating that $a=1$ (i.e., the criterion weight superposition method) is a special case in the OWA algorithm. This finding also validates the scientific robustness of the scenario index selection. As this scenario type and the vulnerability of Yulin City in 2011 correspond to the status quo, we do not go into detail here. From the sustainability-oriented type to the economic priority type, the vulnerability of the social-ecological system in the three scenarios increases, and the spatial distribution is regular. The medium-high and high vulnerability areas are still distributed in the economically developed areas in the north, and the spatial area of high vulnerability obviously expands outward.

(a) Sustainability-oriented type

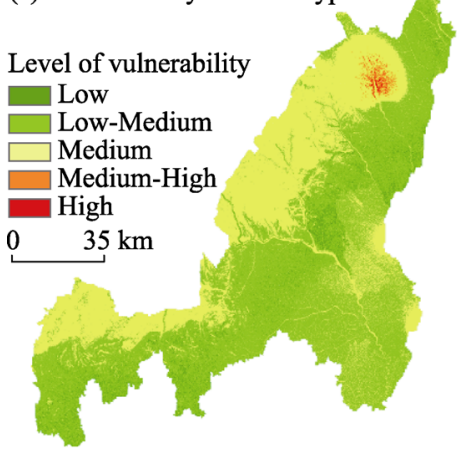

(b) The status quo type

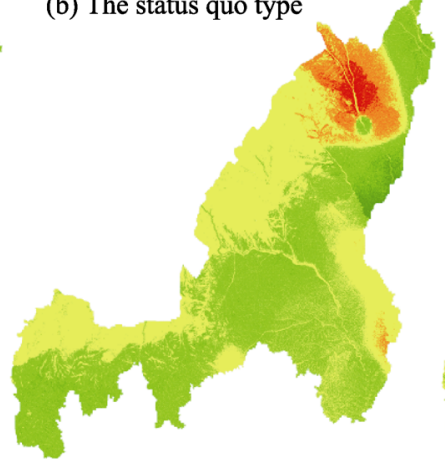

(c) Economic priority type

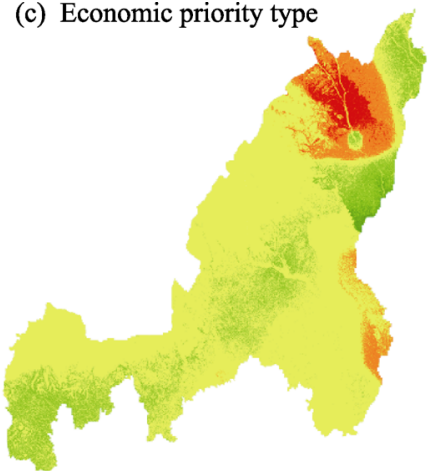

Figure 8 The SESs vulnerability spatial distribution of different scenarios simulation in Yulin city

\footnotetext{
${ }^{2}$ Maintaining the status quo type means the regional development policy on the risk (disaster, eco-environmental problems, etc.) control is not strong, and the speed of socio-economic development remains normal. The economic priority type refers to the government's regional development policy formulation, which is dominated by the speed of economic development and reduces considerations of the eco-environmental problems and natural disaster risk to a certain extent. The sustainability-oriented type refers to regional policy development that emphasizes investment in eco-environment management, increasing disaster risk control, prioritizing sustainable development, reducing the dependence on the energy economy, and changing the model of socio-economic development.
} 
In the economic priority type policy scenario $(a=1.2)$, shown in Figure 8, the medium-vulnerability area is distributed in the sandstorm arid region in the northwest and in regions prone to soil erosion in the southwest. The high-vulnerability region extends from the intensive Shenmu-Fugu mining area outward, and the whole regional system of Yulin City is characterized by medium-high vulnerability. According to Table 4, the order weight of risk indicators in the $a>1$ scenario is large, and the weight of adaptive capacity factors is small, which indicates that economic development ignores environmental stress and lacks emphasis on adaptive capacity, which will lead to an increase in system vulnerability.

In the sustainability-oriented type scenario $(a=0.8)$, the southern counties and areas along the Great Wall in Yulin City are basically low-vulnerability areas, and the vulnerability degree in the northern counties is significantly lower than in other scenarios. As shown in Table 4, the order weights of drought, soil erosion and other risk exposure factor are small in the $a<1$ scenario; that is, risk control and governance measures have been taken, and the emphasis is placed on the index unit with large order weight. This scenario focuses on the environment, technology, social resources, economic development, disaster prevention and mitigation resources as the main factors for building regional adaptive capacity. Therefore, the system vulnerability is significantly decreased, almost the whole region exhibits low-vulnerability, and the high-vulnerability region distribution is very small.

In the above scenario simulations, we can see that different decision risk coefficients result in different vulnerability prediction results for policy-making. Using the multi-scene combination, the OWA algorithm identifies the uncertainty range of the threshold variation of the indexes and predicts the spatial distribution of vulnerability in the study area through the scenario policy, thereby weighing the relationship between "economic development" and "risk control". In the practical policy formulation, the scenario analysis is not a single optimization of the scheme but takes the floating range of vulnerability of the three scenarios as a reference, which can be adjusted according to the regional development strategy in different stages. In particular, based on the assessment results of the system vulnerability in 2000-2015, during this stage, the regional social-ecological system of Yulin City should carry out vulnerability level zoning. On the one hand, the high-vulnerability region should be strictly controlled to reduce the exposure risk stress of coal and other energy bases, and the landscape reconstruction should be carried out in the areas of high soil erosion and the sandstorm arid area in the northwest. On the other hand, attention should be paid to the high exposure risk source in low vulnerability counties. Guiding and supporting the modern agriculture and industrial economy in southern counties are important to maintaining a regional development balance and narrowing the north-south system vulnerability gap. For future policy formulation, the risk coefficient selection of the critical threshold of the system vulnerability depends on the decision makers' awareness of regional development. Based on the influence on the evaluation results of the criteria weight and order weight of scenario indexes, decision makers can identify the key scenario index of the critical point of the system vulnerability to adapt decision-making ideas to the regional development and to achieve rational and scientific policy-making.

\section{Discussion}

In this study, county-level data and the VSD evaluation framework were used as practical guidance for the evaluation of vulnerability. However, our study found that there were limi- 
tations in the multi-scale vulnerability integration analysis, and it was easy to ignore the small-scale factors, such as the human vulnerability, during a comprehensive analysis. Thus, the VSD framework is not a general vulnerability assessment framework. Using the VSD integrated analysis framework can provide specific steps for the vulnerability evaluation of a regional-scale system in this study. The purpose of this research is to realize the operability of the VSD analysis framework via the integration of the SERV model and the OWA algorithm to ensure the reliability and effectiveness of the research. Therefore, the comprehensive application of different methods of vulnerability integration analysis can provide a realistic reference for future construction of a general vulnerability assessment framework (model).

The SERV model not only provides a screening index system and the index selection of specific vulnerability factors at the county level but also advocates evaluation analysis focusing on resource input for disaster reduction in high-vulnerability areas instead of exposure areas. This promotes the evolution of vulnerability evaluation thinking and avoids the defects of traditional vulnerability research. However, the operability of the specific implementation of this model remains to be optimized; for example, the SERV model is limited to a static vulnerability equation, which fails to consider the contribution differences of exposure, sensitivity, and adaptive capacity to vulnerability. Secondly, the selection and construction of an index system by using the SERV model is still in the exploratory stage and needs to be further perfected and verified. In addition, we found that the improved model could determine the specific vulnerability impacts of indicators in specific locations, thus guiding the mitigation and adaptive strategies for specific locations.

Scenario analysis, a common means of assessing geography-ecological processes, has two different ways of induction: one relies on choosing the optimal value in the assumed several scenarios as the final result, and the other relies on the mutual confirmation of several scenarios to achieve a comprehensive conclusion of the pros and cons (Liu et al., 2014). In this paper, for future vulnerability prediction, the OWA algorithm provides a flexible multi-scenario reference for decision makers and a policy-making method that can be adjusted according to the actual situation indicators (elements) of a given area. Simple system dynamics, artificial neural networks and artificial intelligence simulations provide a fixed optimal prediction scheme for the future but cannot simulate subjective uncertainty indicators and are difficult to use in actual policy-making by decision makers. Comparatively speaking, the flexibility of these methods is also weak. In the vulnerability evaluation with the OWA algorithm, the calculation and application of criterion weight and order weight of indexes is the key to its evaluation and are also the key to the existence of rationality and flexibility.

\section{Conclusions}

From the perspective of integration analysis of human-environment relationship, taking the semi-arid SESs in Yulin city as the object of vulnerability evaluation, this paper uses the VSD evaluation framework and integrates multiple methods and multi-index elements to achieve innovative vulnerability assessments and practice methods at the regional scale. This work expands the vulnerability assessment research from a single vulnerability index to a system integration research level that includes vulnerability assessment, evolution, and simulation. Through the index organization method of the SERV model and the VSD framework, the method of index selection and construction is improved, and the integration of multiple risks, the multi-factor natural environment and socio-economic indexes is de- 
scribed to better understand the spatial characteristics and evolution of the social-ecological system vulnerability. The OWA scenario simulation provides technical references for policy-making by decision makers.

The main conclusions are as follows: (1) the social-ecological vulnerability of the study area during the period 2000-2015 shows the spatial pattern of "high in the northwest and the southeast and low along the Great Wall"; the medium-vulnerability level is dominant; the high-vulnerability region is concentrated in the northern energy economy-dependent counties and the compact mining area. Over the 16 years, the evolution of the social-ecological system vulnerability of Yulin City has gradually improved; the regional area of high and medium vulnerability has decreased, and the spatial distribution of the low-vulnerability region has shifted southward. (2) The spatial heterogeneity of system vulnerability and exposure risk is significant. The system vulnerability of the northern counties dominated by high exposure-vulnerability is related to natural disaster disturbances and high-intensity human activities that are destroying ecosystems, while the low exposure-vulnerability of the southeastern counties, which have unbalanced development of the society system, is related to high social sensitivity and low economic adaptive capacity. (3) Based on the process simulation of the dynamic evolution of vulnerability via the OWA algorithm and the vulnerability spatial pattern prediction of the three scenarios, it can meet the decision-making needs of regional sustainable development under different policy goals.

\section{References}

Acosta-Michlik L, Espaldon V, 2008. Assessing vulnerability of selected farming communities in the Philippines based on a behavioural model of agent's adaptation to global environmental change. Global Environmental Change, 18(4): 554-563.

Adger W N, 2006. Vulnerability. Global Environmental Change, 16: 268-281.

Al-Kalbani M S, Price M F, Abahussain A et al., 2014. Vulnerability assessment of environmental and climate change impacts on water resources in Al Jabal Al Akhdar, Sultanate of Oman. Water, 6: 3118-3135;

Chen C C, Xie G D, Zhen L et al., 2008. Analysis of Jing he watershed vegetation dynamics and evaluation of its relation to precipitation. Acta Ecologica Sinica, 28(3): 925-938. (in Chinese)

Chen P, Chen X L, 2010. Summary on research of coupled human-environment system vulnerability under global environmental change. Progress in Geography, 29(4): 454-462. (in Chinese)

Ciftcioglu G C, 2017. Assessment of the resilience of socio-ecological production landscapes and seascapes: A case study from Lefke Region of North Cyprus. Ecological Indicators, 73: 128-138.

Cumming G S, 2011. Spatial Resilience in Social-Ecological System. University of Cape Town: Springer Press.

Duan C, 2005. Regional sustainable development evaluation index system and comprehensive evaluation. Technoeconomics \& Management Research, (3): 27-28. (in Chinese)

Frazier T G, Thompson C M, Dezzani R J et al., 2014. A framework for the development of the SERV model: A spatially explicit resilience-vulnerability model. Applied Geography, 51: 158-172.

Frazier T G, Thompson C M, Dezzani R J et al., 2013. Spatial and temporal quantification of resilience at the community scale. Applied Geography, 42: 95-107.

Gómez-Ortiz A, Oliva M., Salvà-Catarineu M et al., 2013. The environmental protection of landscapes in the high semiarid Mediterranean mountain of Sierra Nevada National Park (Spain): Historical evolution and future perspectives. Applied Geography, 42: 227-239.

Holling C S, 2001. Understanding the complexity of economic, ecological, and social systems. Ecosystems, 4: 390-405.

Huang J Y, Liu Y, Ma L et al., 2012. Review on the theoretical model and assessment framework of foreign vulnerability research. Areal Research and Development, 31(5): 1-15. (in Chinese)

IPCC, 2014. Climate Change 2014. Impacts, adaptation, and vulnerability Part B: Regional aspects. In: Working Group II Contribution to the Fifth Assessment Report of the Intergovernmental Panel on Climate Change. Cambridge: Cambridge University Press.

Jones B, Andrey J, 2007. Vulnerability index construction: Methodological choices and their influence on identifying vulnerable neighborhoods. International Journal of Emergency Management, 4(2): 269-295.

Li F M, Xu J Z, Sun G J, 2003. Restoration of degraded ecosystems and development of water-harvesting ecological agriculture in the semi-arid Loess Plateau of China. Acta Ecologica Sinica, 23(9): 1901-1909. (in Chinese) 
Lin N F, Tang J, 2001. Study on the environmental evolution and the causes of desertification in arid and semiarid regions in China. Scientia Geographica Sincia, 21(1): 24-29. (in Chinese)

Liu X L, Ren J Z, 2002. Landscape ecological mechanism on system coupling of the meta-ecosystem consisted of mountain, desert and oasis in Hexi corridor,Gansu,China. Chinese Journal of Applied Ecology, 13(8): 979-984. (in Chinese)

Liu Y X, Peng J, Han Y N et al., 2014. Suitability assessment for building land consolidation on gentle hillside based on OWA operator: A case in Dali Bai Nationality Borough in Yunnan, China. Acta Ecologica Sinica, 34(12): 3188-3197. (in Chinese)

Lu C P, Chen X P, Wang H J et al., 2013. A study on dynamic simulation of human-natural relationship evolution in Northwest ethnic minority: Case of Gannan. Journal of Natural Resources, 28(7): 1255-1263. (in Chinese)

Nelson D R, Adger W N, Brown K, 2007. Adaptation to environmental change: Contributions of a resilience framework. Annual Review of Environment and Resources, 32: 395-419.

Nguyen A K, Liou Y A, Li M H et al., 2016. Zoning eco-environmental vulnerability for environmental management and protection. Ecological Indicators, 69: 100-117.

Patterson T, Guldenb T, Cousins K et al., 2004. Integrating environmental, social and economic systems: A dynamic model of tourism in Dominica. Ecological Modelling, 175: 121-136.

Perry R I, Ommer R E, Barange M et al., 2010. The challenge of adapting marine social-ecological systems to the additional stress of climate change. Current Opinion in Environmental Sustainability, 2: 356-363.

Polsky C, Neff R, Yarnal B, 2007. Building comparable global change vulnerability assessments: The vulnerability Sco-ping Diagram .Global Environmental Change, 17(34): 472-485.

Qin W, Zhu Q K, Zhang Y, 2009. Soil erosion assessment of small watershed in Loess Plateau based on GIS and RUSLE. Transactions of the CSAE, 25(8): 157-163. (in Chinese)

Roberts M G, Yang G A, 2003. The international progress of sustainable development research: A comparison of vulnerability analysis and the sustainable livelihoods approach. Progress in Geography, 22(1): 11-21.

Rosa D L, Martinico F, 2013. Assessment of hazards and risks for landscape protection planning in Sicily. Journal of Environmental Management, 127: S155-S167.

Sannwald E H, Palacios M R, Arredondo Moreno J T et al., 2012. Navigating challenges and opportunities of land degradation and sustainable livelihood development in dryland social-ecological systems: A case study from Mexico. Philosophical Transactions of the Royal Society B, 367: 3158-3177.

Shi P J, Wang M, Hu X B et al., 2014. Integrated risk governance consilience mode of social-ecological systems. Acta Geographica Sinica, 69(6): 863-876. (in Chinese)

Smit B, Wandel J, 2006. Adaptation, adaptive capacity and vulnerability. Global Environmental Change, 16 (3): 282-292.

Speranza C I, Wiesmann U, Rist S, 2014. An indicator framework for assessing livelihood resilience in the context of social-ecological dynamics. Global Environmental Change, 28: 109-119.

Stoetzel E, Cornette R, Lalis A et al., 2017. Systematics and evolution of the Meriones shawii/grandis complex (Rodentia, Gerbillinae) during the Late Quaternary in northwestern Africa: Exploring the role of environmental and anthropogenic changes. Quaternary Science Reviews, 164: 199-216.

Sun P, Zhang Q, Bai Y G et al., 2014. Transitional behaviors of hydrometeorological droughts in Xinjiang using the Markov chain model. Geographical Research, 33(9): 1647-1657. (in Chinese)

Tian Y P, Xiang Q C, Wang P, 2013. Regional coupled human-natural systems vulnerability and its evaluation indexes. Geographical Research, 32(1): 55-63. (in Chinese)

Turner B L, Kasperson R E, Matson P A, 2003. A framework for vulnerability analysis in sustainability science. In: Proceedings of the National Academy of Sciences of the United States of America, 8074-8079.

Wang G J, Liao S G, 2006. Spatial heterogeneity of land use intensity. Chinese Journal of Applied Ecology, 17(4): 611-614. (in Chinese)

Wang G X, Chen G D, Shen Y P, 2002. Features of eco-environmental changes in Hexi Corridor Region the last 50 years and comprehensive control strategies. Journal of Natural Resources, 17(1): 78-86. (in Chinese)

Wang Y, Wang J S, Yao Y B, 2014. Assessment and regionalization on meteorological drought disaster risk in the Hedong area of Gansu province, China. Journal of Desert Research, 34(4): 1115-1124. (in Chinese)

Xin Z B, Xu J X, Yu X X, 2009. Temporal and spatial variability of sediment yield on the Loess Plateau in the past 50 years. Acta Ecologica Sinica, 29(3): 1129-1139. (in Chinese)

Yager R R, 1988. On ordered weighted averaging aggregation operators in multi-criteria decision making. IEEE Transactions on Systems, Man and Cybernetics, 18(1): 183-190.

Yager R R, 1996. Quantifier guided aggregation using OWA operators. International Journal of Intelligent Systems, 11(1): 49-73.

Yang X J, Shi Y Z, Wang Z Q, 2015. Exploring the impacts of road construction on a local social-ecological system in Qinling mountainous area: A resilience perspective. Acta Geographica Sinica, 70(8): 1313-1326. (in Chinese)

Zhao H L, Zhao X Y, Zhang T H et al., 2011. Desertification process and its spatial differentiation in arid areas of Northwest China. Journal of Desert Research, 31(1): 1-8. (in Chinese)

Zhang J X, Zhang B, Zhang H et al., 2011. Landscape pattern change and soil erosion research: Take Malian River Basin in Loess Plateau as an example. Journal of Natural Resources, 26(9): 1513-1525. (in Chinese) 